\title{
The prevalence of metabolic syndrome up to 5 years post-partum in patients with a history of gestational diabetes mellitus
}

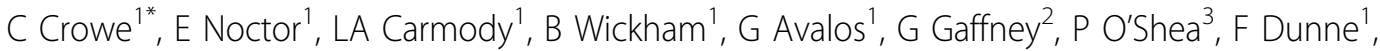 \\ the ATLANTIC DIP Collaborators
}

From International Conference for Healthcare and Medical Students 2011

Dublin, Ireland. 4-5 November 2011

\section{Introduction}

Metabolic syndrome (MetS) is associated with cardiovascular mortality and increased risk of type 2 diabetes.

\section{Methods}

We examine the prevalence of MetS in a cohort of Caucasian women with previous gestational diabetes (GDM) $(\mathrm{n}=116)$, and those with normal glucose tolerance (NGT) during pregnancy $(\mathrm{n}=51)$. Fasting glucose alone (known $\mathrm{DM} /$ pre-diabetes post-partum patients) or $75 \mathrm{~g}$ OGTT (other patients), lipid profile, insulin and c-peptide were performed. We calculated insulin resistance using the HOMA2-IR computer model.

\section{Results}

\section{Conclusions}

Metabolic syndrome and insulin resistance are significantly more prevalent in Caucasian patients with GDM progressing to post-partum DM/pre-diabetes than those who do not $(\mathrm{p}<0.01)$, suggesting a need to target lifestyle changes in the early post-partum period to help prevent progression to T2DM.

\section{Author details}

${ }^{1}$ Department of Medicine, University Hospital Galway and National University of Ireland, Galway, Ireland. '2Department of Obstetrics and Gynaecology, University Hospital Galway, Ireland. ${ }^{3}$ Department of Clinical Biochemistry, University Hospital Galway, Ireland.

Published: 9 July 2012

\section{doi:10.1186/1753-6561-6-S4-P44}

Cite this article as: Crowe et al:: The prevalence of metabolic syndrome up to 5 years post-partum in patients with a history of gestational diabetes mellitus. BMC Proceedings 2012 6(Suppl 4):P44.

Table 1

\begin{tabular}{llll}
\hline & Number with MetS (ATPIII criteria) (\%) & Mean HOMA-2IR (+/- SD) & Number with HOMA-2IR>1.7 (\%) \\
\hline DM/pre-diabetes post GDM $(\mathrm{n}=33)$ & $12(36 \%)$ & $1.21(+/-0.77)$ & $18(55 \%)$ \\
NGT post GDM $(\mathrm{n}=83)$ & $11(13 \%)$ & $1.93(+/-1.4)$ & $18(22 \%)$ \\
No history GDM $(\mathrm{n}=52)$ & $3(6 \%)$ & $1.02(+/-0.85)$ & $6(13 \%)$ \\
\hline
\end{tabular}

'Department of Medicine, University Hospital Galway and National University

of Ireland, Galway, Ireland

Full list of author information is available at the end of the article

C Biomed Central

(c) 2012 Crowe et al; licensee BioMed Central Ltd. This is an Open Access article distributed under the terms of the Creative Commons Attribution License (http://creativecommons.org/licenses/by/2.0), which permits unrestricted use, distribution, and reproduction in any medium, provided the original work is properly cited. 